\title{
Immersive virtual reality health games: a narrative review of game design
}

\author{
Gordon Tao ${ }^{1 *} \mathbb{0}$, Bernie Garrett², Tarnia Taverner ${ }^{2}$, Elliott Cordingley ${ }^{3}$ and Crystal Sun ${ }^{2}$
}

\begin{abstract}
Background: High quality head-mounted display based virtual reality (HMD-VR) has become widely available, spurring greater development of HMD-VR health games. As a behavior change approach, these applications use HMDVR and game-based formats to support long-term engagement with therapeutic interventions. While the bulk of research to date has primarily focused on the therapeutic efficacy of particular HMD-VR health games, how developers and researchers incorporate best-practices in game design to achieve engaging experiences remains underexplored. This paper presents the findings of a narrative review exploring the trends and future directions of game design for HMD-VR health games.
\end{abstract}

Methods: We searched the literature on the intersection between HMD-VR, games, and health in databases including MEDLINE, Embase, CINAHL, PsycINFO, and Compendex. We identified articles describing HMD-VR games designed specifically as health applications from 2015 onwards in English. HMD-VR health games were charted and tabulated according to technology, health context, outcomes, and user engagement in game design.

Findings: We identified 29 HMD-VR health games from 2015 to 2020, with the majority addressing health contexts related to physical exercise, motor rehabilitation, and pain. These games typically involved obstacle-based challenges and extrinsic reward systems to engage clients in interventions related to physical functioning and pain. Less common were games emphasizing narrative experiences and non-physical exercise interventions. However, discourse regarding game design was diverse and often lacked sufficient detail. Game experience was evaluated using primarily ad-hoc questionnaires. User engagement in the development of HMD-VR health games primarily manifested as user studies.

Conclusion: HMD-VR health games are promising tools for engaging clients in highly immersive experiences designed to address diverse health contexts. However, more in-depth and structured attention to how HMD-VR health games are designed as game experiences is needed. Future development of HMD-VR health games may also benefit from greater involvement of end-users in participatory approaches.

Keywords: Virtual reality, Head mounted display, HMD, Health game, Exergame, Rehabilitation games

\section{Background}

In recent years, there has been a rapid growth in the reported use of virtual reality (VR) in the treatment of a variety of clinical conditions, such acute and chronic pain

*Correspondence: gordon.tao@ubc.ca

${ }^{1}$ Graduate Programs in Rehabilitation Science, Faculty of Medicine, University of British Columbia, Vancouver, BC, Canada

Full list of author information is available at the end of the article management [1-3], phobias, anxiety and other disorders or health conditions [4-13]. VR as a concept has come to include a wide range of digital technology applications where the user perceives and interacts with a computer-generated virtual environment, whether through a traditional 2-dimensional (2D) display, a projected display paired with 3D glasses, or a head-mounted display (HMD). Given such diverse types of display technologies, comparisons may not be reliable, and so this review is original author(s) and the source, provide a link to the Creative Commons licence, and indicate if changes were made. The images or other third party material in this article are included in the article's Creative Commons licence, unless indicated otherwise in a credit line to the material. If material is not included in the article's Creative Commons licence and your intended use is not permitted by statutory regulation or exceeds the permitted use, you will need to obtain permission directly from the copyright holder. To view a copy of this licence, visit http://creativecommons.org/licenses/by/4.0/. The Creative Commons Public Domain Dedication waiver (http://creativeco mmons.org/publicdomain/zero/1.0/) applies to the data made available in this article, unless otherwise stated in a credit line to the data. 
focused on HMD-VR technology applications. Similarly, general software content of HMD-VR ranges from artistic virtual experiences, to simulations, to games. This review focuses on games designed specifically as health applications, or HMD-VR health games.

\section{Advances in HMD-VR technology}

Research in the 1980's with early computer graphics explored the potential for computer-generated VR experiences with HMDs. At the time, computer processing power was very limited while HMDs were unreliable and cost tens of thousands of dollars. More recently, commercially available computer and graphics technology has become capable of rendering realistic high resolution 3D imagery in real-time. The current level of technology is far removed from devices we were using in research even five years ago (such as the Oculus Rift Development Kit 2). In 2005, basic cloth simulation was hailed as showpiece technology, whilst modern 3D rendering cards with integrated physics support can simulate individual human hair movement in complex lighting situations. This technological progress has made modern VR devices much more immersive, providing a much better sense of presence for demanding VR gaming users, and more importantly, less prone to technical problems than their early counterparts. Whilst the typical cost of a high-end consumer HMD-VR set-up remains high for individual consumers ( $\$ 2000$ or more, including gaming computer and headset system), this generation of technology has seen substantial use in research settings [14]. Moreover, VR technology companies have released more accessible, affordable, and easy to use HMDs, e.g. Oculus Quest (Facebook, Menlo Park, USA). These advancements will support greater accessibility of HMD-VR, including HMD-VR health applications.

\section{Applying gaming and HMD-VR in health}

The key element in these HMD-VR health applications is the use of immersive media content to engage the users in a stimulating interactive experience, where they feel a sense of presence in a different and novel environment $[14,15]$. This is quite different from two-dimensional computer based gaming implementations. Presence here, refers to the sense of actually being within an environment that is generated by technological means [14, 16-18]. It involves the participant as a co-constructor of the experience, and this concept is well-established in computer science [14]. Although third-person perspectives have been used and discussed in VR gaming experiences, this has not been a major focus for health game application developers, as the potential for VR to engender a sense of first-person presence represents one of its main attractions $[19,20]$. Hence, this review has focused on HMD VR implementations, as the most common and rapidly developing field in VR health gaming applications.

The typical content takes the form of either a game or a purposeful, yet non-gaming, first-person virtual experience. A common application of the latter is seen in exposure therapy whereby patients with phobias are presented with the source of their anxiety or fear in a controlled and graded manner in order to help them overcome their distress response [21]. Another example is Virtual Meditative Walk where users follow a guided meditation to reduce anxiety and chronic pain. In this virtual environment, EEG biofeedback of entering relaxed mindful state causes mist to appear in the virtual forest [22]. Alternatively, off-the-shelf commercial HMD-VR games may be used as novel adjunctive interventions. Exercise-based games such as Audioshield [23] and Beat Saber [24] are rhythm-based HMD-VR games where players have to physically move their bodies to play. Beyond cardiovascular exercise, such games are of therapeutic interest for their involvement of psychomotor skills and even cognitive skills. Yet, the principal appeal behind using games for therapy, whether HMD-based or not, has been their potential to support sustained adherence to therapy [27-29]. As such, game-based therapy may be viewed as an approach to behavior change [30]. However, off-theshelf commercial HMD-VR games are limited in their application. As they are designed for general able-bodied audiences, they may not be suitable for health contexts involving physical or cognitive limitations.

Another approach has involved developing games specifically as health applications [31-33]. For example, rehabilitation games for stroke recovery have seen technology implementations pairing motion capture technology with both 2D televisions and HMDs [34]. Health games are usually designed to address limitations in body functions or mental health, build specific skills, or promote positive behaviors in the player. They often involve combining elements such as puzzles, graded difficulty, matching patterns, repetitive exercises, exploring an environment, or simply providing a pleasing and distracting experience. An early example includes Hunter Hoffman's SnowWorld, which used an older generation of HMD-VR technology. In SnowWorld, patients who had suffered burns throw snowballs at snowmen and penguins to reduce their pain $[38,39]$. Such HMD-VR health games aim to combine the advantages of a fun and motivating game with clinically grounded approahces.

\section{Game design for HMD-VR health applications}

Developing games as health applications using HMDVR requires a broad intersection of theoretical and technical lenses. These include biomedical and psychosocial perspectives on health, computer and engineering 
technologies, human computer interaction theory, and ultimately game design. Several approaches to game design have been articulated by Salen and Zimmerman [35], Schell [36], and Fagerholt and Lorentzon [37]. Games may be fundamentally described as systems with defined rules, explicit objectives, and quantifiable outcomes, whereby interaction with these systems give rise to a playful experience [36]. These systems may be contrasted with other artefacts such as playgrounds, where there are no game rules, or training simulators, where play is not an important aspect of the experience. The ultimate design goal, according to Salen and Zimmerman, is an experience of meaningful play, which "occurs when the relationships between actions and outcomes in a game are both discernable and integrated into the larger context of the game" [35].

Considering Hunicke and colleague's MechanicsDynamics-Aesthetics (MDA) framework [38], meaningful play can be understood through the Aesthetic experiences produced by a game such as fantasy, challenge, discovery, self-expression, etc. These Aesthetic experiences are the cumulative emotional and intellectual product of the game Dynamics: the various ways the player interacts, makes choices, and plays the game. Examples of Dynamics include resource management, time pressure, cooperation, collection, building, or other strategies. Underpinning the game Dynamics are the Mechanics that make up the objects and rules of the game. For example, Mechanics in Chess include the board layout, the different pieces, how the pieces can move and capture other pieces, and the objective and outcome of checkmating your opponent. With this conception of games in mind, we may consider the strengths and benefits of using HMD-VR for gameplay experiences and their impact in context of health applications. Primarily, HMD-VR greatly contributes to aesthetic experiences that rely on sensory immersion, e.g. discovery and fantasy.

Moreover, the quality of game design ultimately impacts stakeholder adoption of these games as health technology [39-41]. To this end, stakeholder engagement throughout the research and development process has also seen increasing emphasis [39, 42, 43]. Overall, HMD-VR health games represents a growing field, and some researchers are now beginning to compare the value of different hardware and software applications in this area [44]. Reviews including HMD-VR health games typically focus on efficacy in a specific context $[2,21$, 45]. However, it is unclear how differences in the game design of HMD-VR health games impact their effectiveness compared to others. Often, broad comparisons are made in terms of very different systems, users, and assessment tools. We are gaining some ideas about the important elements in designing user accessible and effective HMD-VR experiences overall [14, 46, 47], but within this sphere, the value of good game design in the effectiveness of a health game remains relatively unexplored. Yet, it represents a significant part of the puzzle. Game design underpins the mechanisms by which HMDVR health games influence patients as a behavior change approach. Therefore, an exploration of the application of game-design in HMD-VR is a significant and worthwhile area to explore further. To this end, we conducted a narrative review characterizing the current state and considerations of game design in HMD-VR health games.

\section{Methods}

To explore game design in HMD-VR health games, a literature search focusing on the intersection between HMD-VR, games, and health was undertaken. Bibliographic health databases searched included MEDLINE, Embase, CINAHL, and PsycINFO. The engineering database Compendex with a search restriction to the "health" topic was also used. To narrow VR-related literature to only HMD-VR, the keywords: HMD, head mounted display, and virtual headset were used as search terms. For games, the keywords: game, gaming, and exergame were used. Search results were restricted to the English language. To capture the current generation of HMD-VR we also restricted results to those published from 2015 onwards. All search results arising from the Boolean "AND" of the HMD-VR and games search results were screened. Title and abstract screening included any articles mentioning VR or games in a health context. The full text screening criteria are provided in Table 1.

HMD-VR health games were charted and tabulated according to the type of input technology implementation, health context (i.e. clinical population, condition, or type of intervention), outcomes used in the evaluation of the game, and user engagement employed during game design, if any. Given the wide range of approaches to game design and reporting, a narrative review appeared the most appropriate approach. Accordingly, we summarized each reviewed game according to the MDA framework and narratively described observed trends. Furthermore, we tabulated outcomes related to evaluation of identified games according to therapeutic outcomes, game experience, technology acceptance, cybersickness, and open feedback. Tabulated results were also integrated into each topic of discussion.

\section{Findings}

The complete search was conducted on March 16, 2020 and identified 140 potentially relevant articles. Deduplication yielded 94 unique articles. Title and abstract screening identified 47 articles related to HMD-VR, 
Table 1 Inclusion and exclusion criteria

\begin{tabular}{|c|c|}
\hline Inclusion criteria & Exclusion criteria \\
\hline $\begin{array}{l}\text { Original articles describing the design of a digital application specifically for health contexts (e.g. reducing symptoms, } \\
\text { recovering body or cognitive functions, or maintaining health) } \\
\text { Use a HMD-VR as the display and interaction technology } \\
\text { Describes the VR application as a game } \\
\text { Available in the English language } \\
\text { Published in peer reviewed academic or professional journals }\end{array}$ & $\begin{array}{l}\text { Only used commercially } \\
\text { available HMD-VR games } \\
\text { designed for general audi- } \\
\text { ences } \\
\text { Opinion or narrative discus- } \\
\text { sions that did not report } \\
\text { on the use of a specific } \\
\text { VR-based game } \\
\text { Grey literature }\end{array}$ \\
\hline
\end{tabular}

games, and health. Upon full-text screening, 30 articles were identified as describing HMD-VR games designed specifically for health contexts [48-77]. One article referenced previous work with greater detail related to game design and was retrieved [57]. The 29 HMD-VR games are summarized in Table 2 and evaluation outcomes are characterized in Table 3. All data are provided together in Additional file 1 .

\section{Health contexts and end-users}

Of the HMD-VR health games reviewed, the most common health contexts included physical exercise, motor rehabilitation, and pain related conditions. Physical exercise games were aimed at both healthy adults and those with various health conditions. For example, Tuveri and colleagues designed Rift-a-bike to engage a general audience in cycling-based exercise [49] while Eisapour and colleagues focused on exercise for people with dementia [74]. Other health contexts ranged from addressing sensory disorders [70] to cognitive functioning [53]. Overall, these contexts are consistent with applications found in the broader health VR field, which includes non-game and non-HMD applications [78-80]. However, some key areas were not represented in the games reviewed. While HMD-VR applications have been used for mental health disorders such as phobias, depression, or body dysmorphia, those conditions have not seen HMD-VR health games designed specifically for them [14, 21]. Perhaps, for conditions such as mild depression, off-the-shelf commercial exergames (HMD-VR or otherwise) may suffice for improving certain aspects of function [81]. In such cases, a specifically developed HMD-VR health game may be unnecessary. Nevertheless, commercial gamebased interventions may not always be an appropriate method of treatment delivery for these underrepresented health conditions. More research is necessary to understand how game playing and using HMD-VR, can support or conflict with therapies for such health conditions.

Conversely, HMD-VR games based on therapies involving physical movement were the dominant trend observed. In this context, the choice of interaction technology is particularly important. While HMD-VR provides the principle means of immersing the user in an environment, the quality of motion tracking determines the perceived realism of a user's actions impacting the virtual environment [82]. This technology choice must also be aligned with the therapeutic modality, as each technology has its limitations. For example, skeletal tracking [83] is suitable for health applications involving gross movement over larger ranges of motion, as Sisto and colleagues used skeletal tracking for determining risk of musculoskeletal disorder during gameplay [54]. Conversely, hand tracking [84] is more suitable for exercises involving fine finger control, as seen in VRheab [56]. Therefore, the intersection of the health context with the interaction technology underpins the scope and technical limitations within which HMD-VR health games must be designed.

Intersection of health context with interaction technology HMD-VR health games have relied on the successful commercialization of economical VR headsets with suitable features for entertainment such as high-resolution displays, accessible development tools, and comfort. Moreover, the improved ability to track headsets with six degrees of freedom (i.e. up/down, left/right position and rotation about three perpendicular axes, pitch, roll and yaw) allows for more natural and immersive interaction with virtual environments. Compared to traditional 2-dimensional (2D) displays, playing games within the greater immersion of HMD-VR can lead to overall greater satisfaction, with emphasis on engrossment and creative freedom [85]. From the studies we reviewed, $\mathrm{Xu}$ and colleagues showed greater immersion, effort, flow, and affect in an HMD condition compared to a large 2D display during an exergame [77]. Other studies have demonstrated that HMD-VR heightens emotional responses such as happiness, anxiety, or surprise compared to $2 \mathrm{D}$ displays $[47,86]$. Yet, the application of HMD-VR may also depend on the population and type of intervention. For example, Howes and colleagues [75] found their older adult participants preferred a 2D display over HMD 


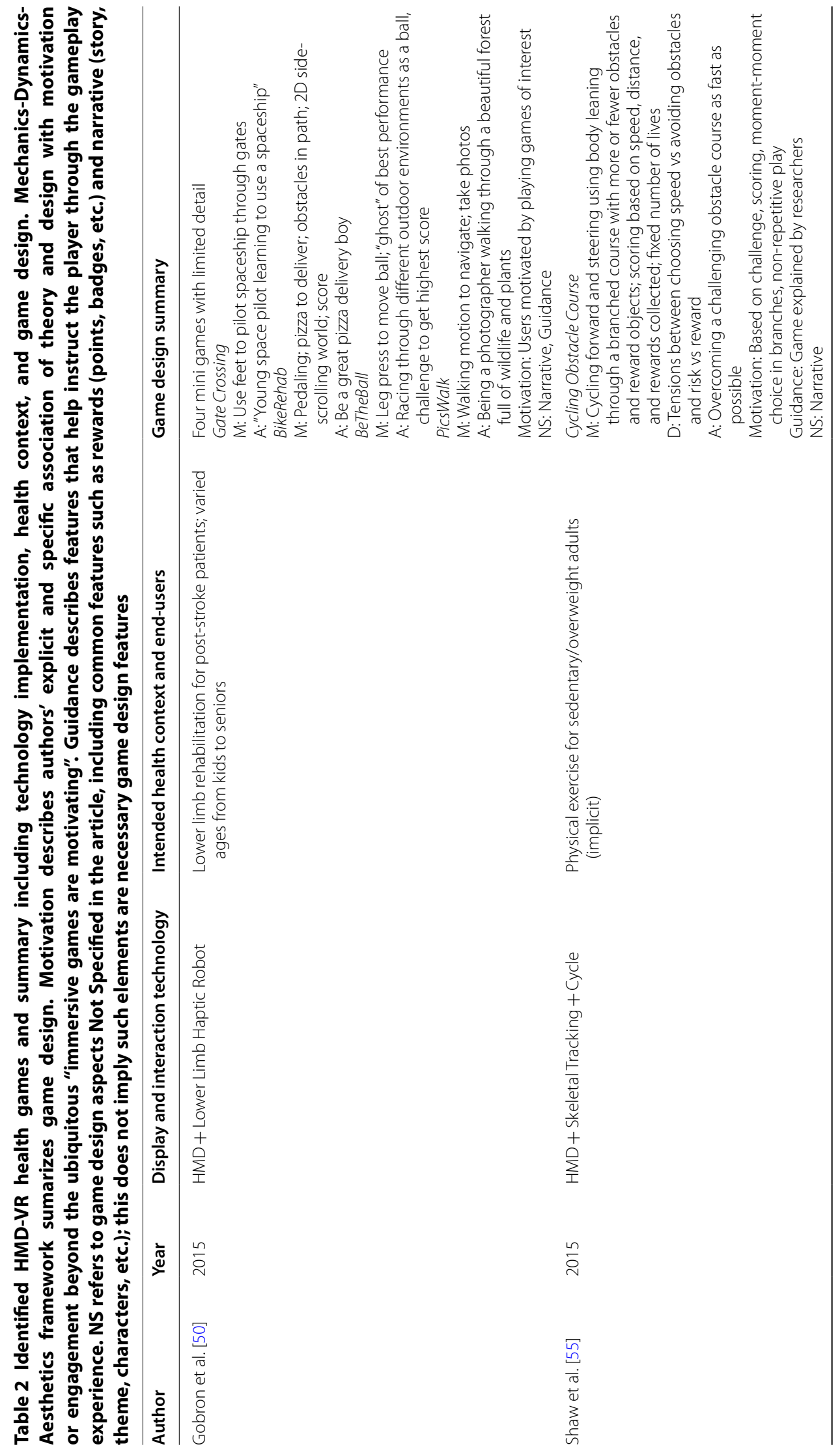




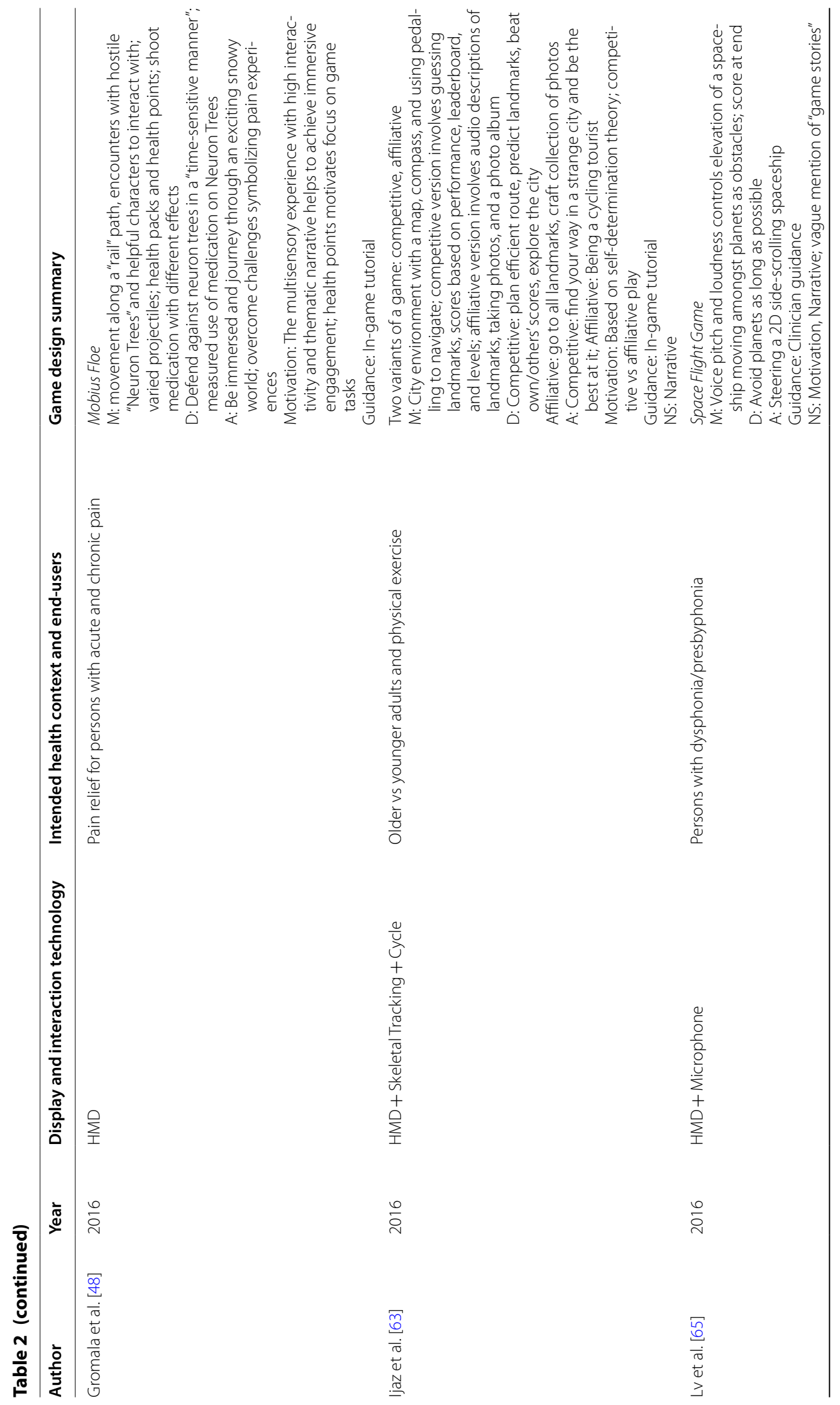


Tao et al. J NeuroEngineering Rehabil ～～(2021) 18:31

Page 7 of 21

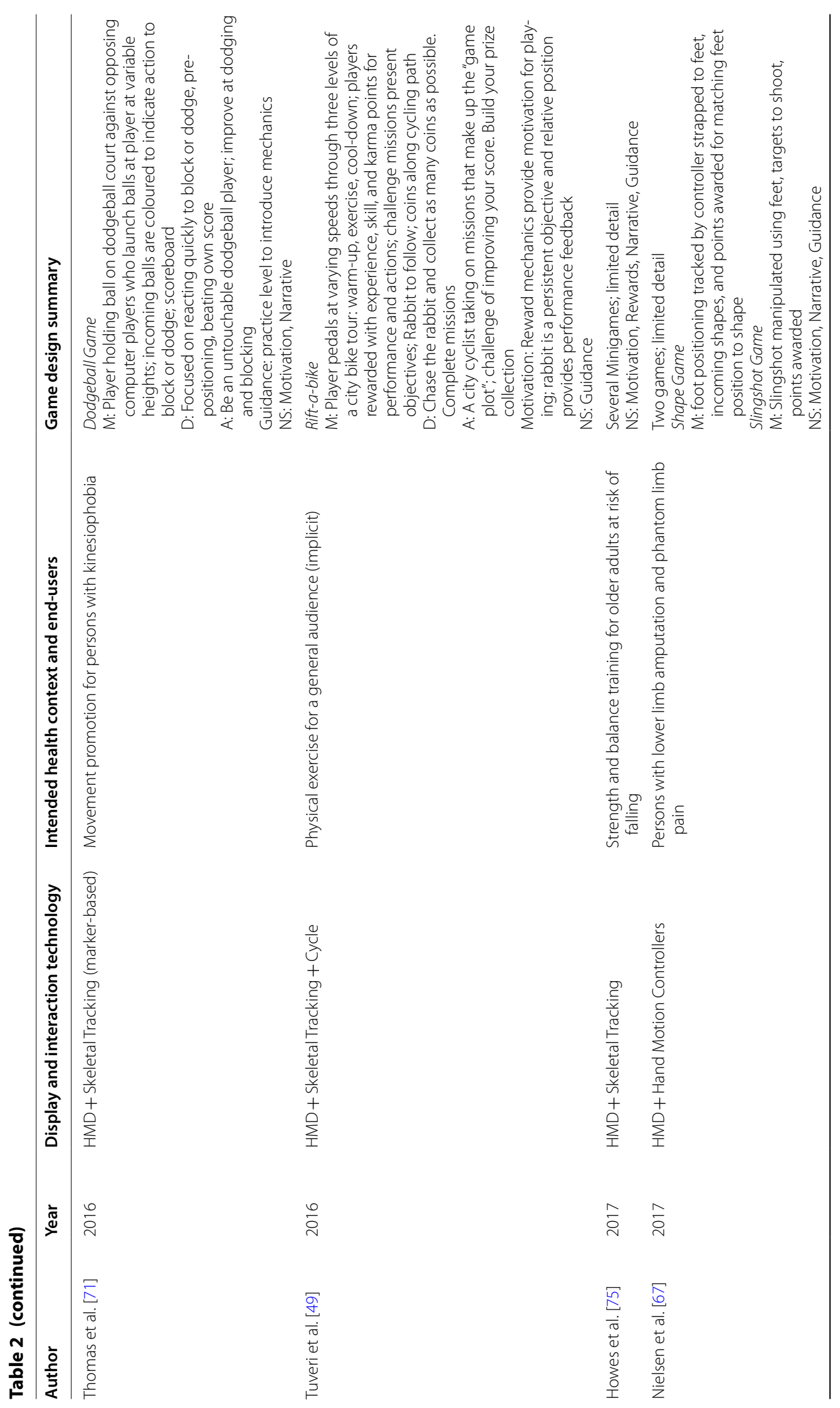


Tao et al. J NeuroEngineering Rehabil (2021) 18:31

Page 8 of 21

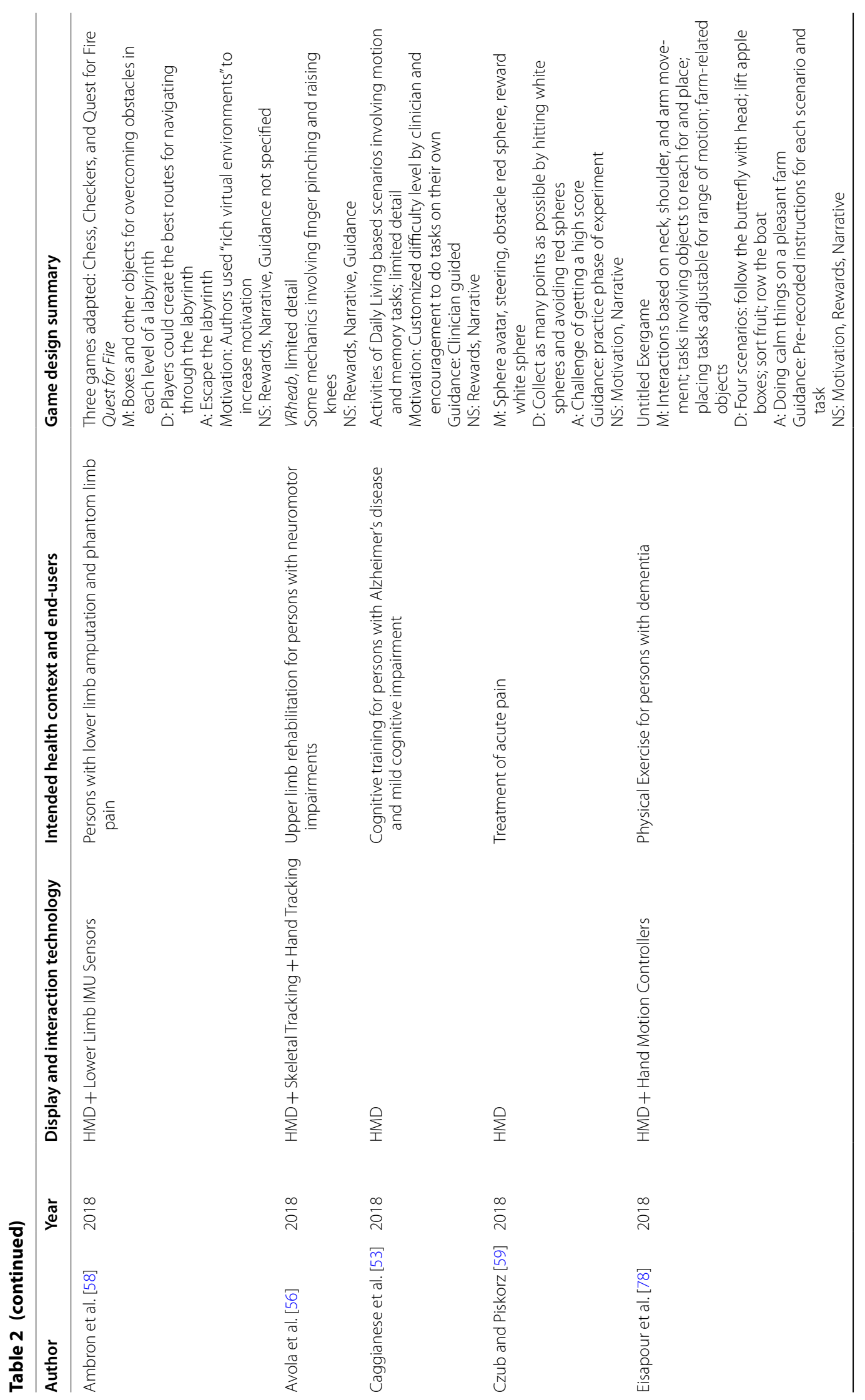




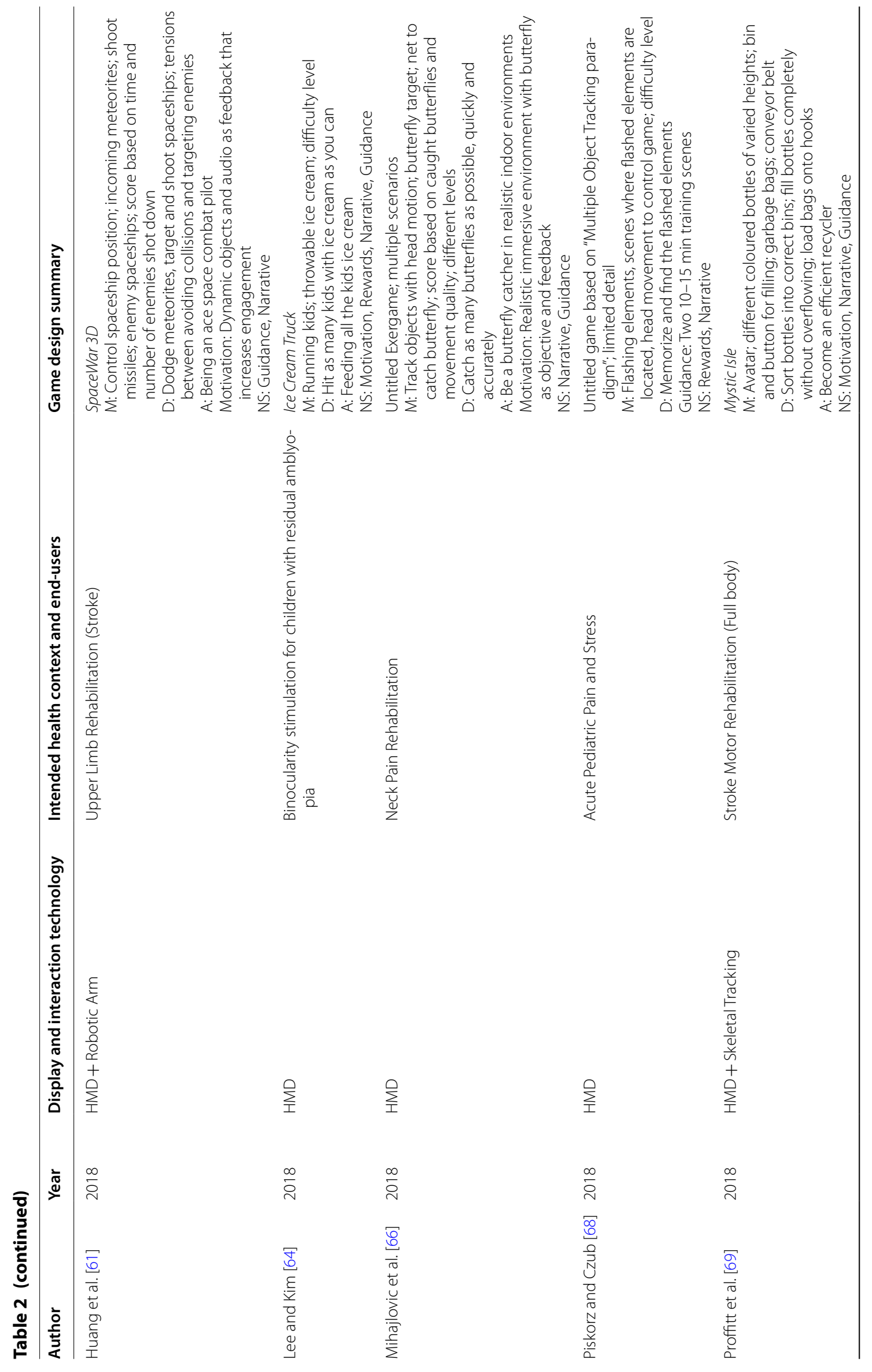


Tao et al. J NeuroEngineering Rehabil (2021) 18:31

Page 10 of 21

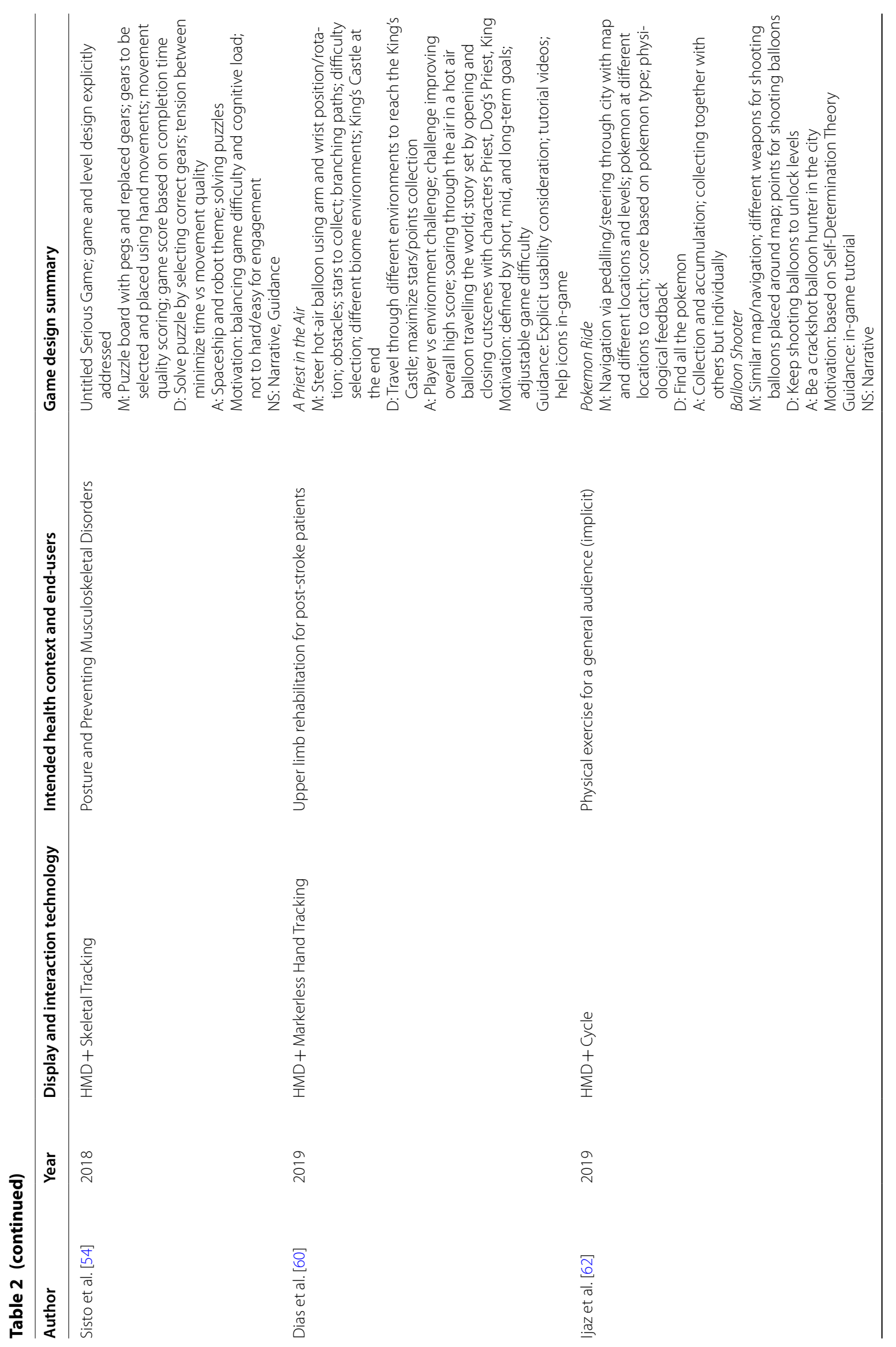


Tao et al. J NeuroEngineering Rehabil (2021) 18:31

Page 11 of 21

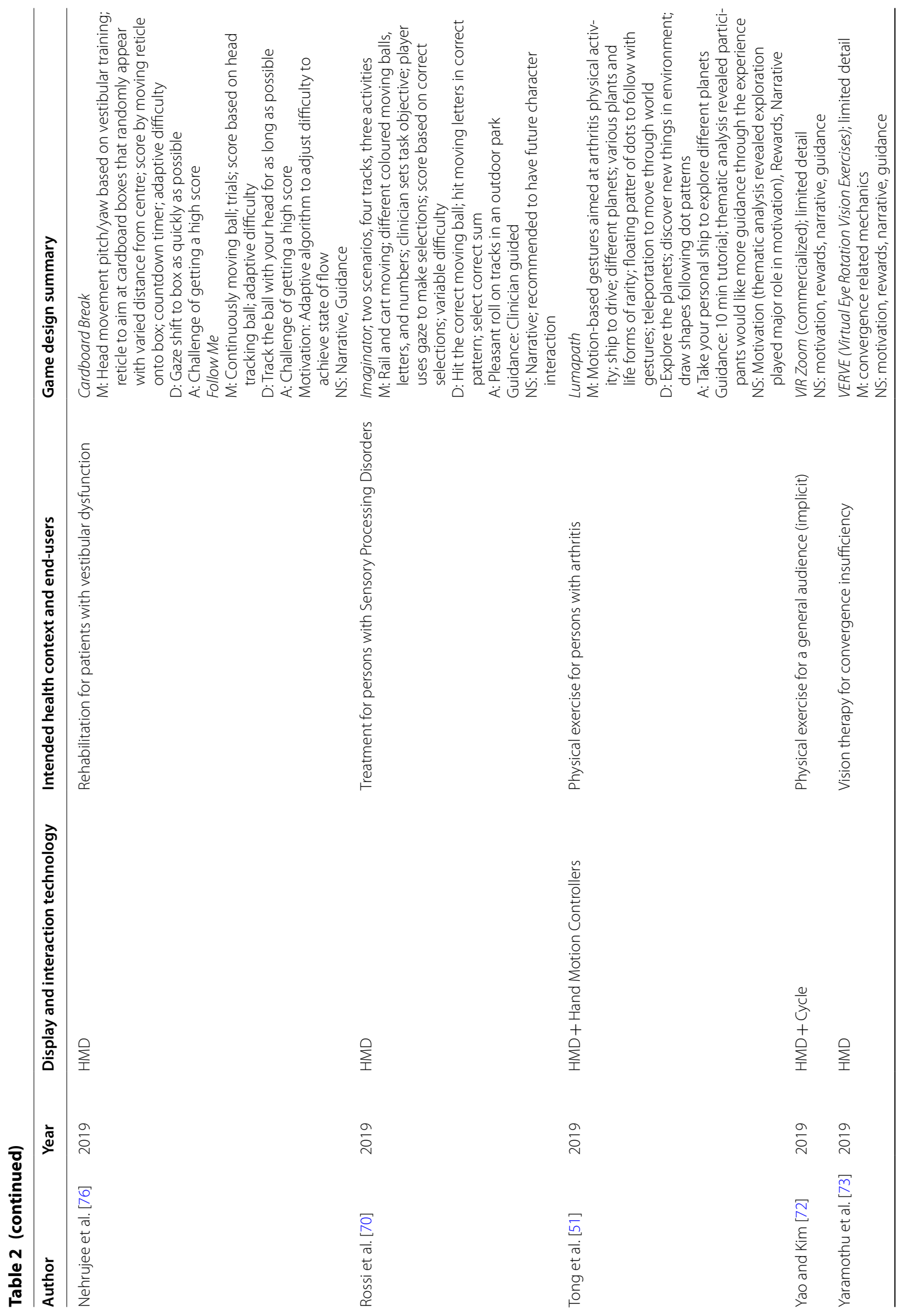




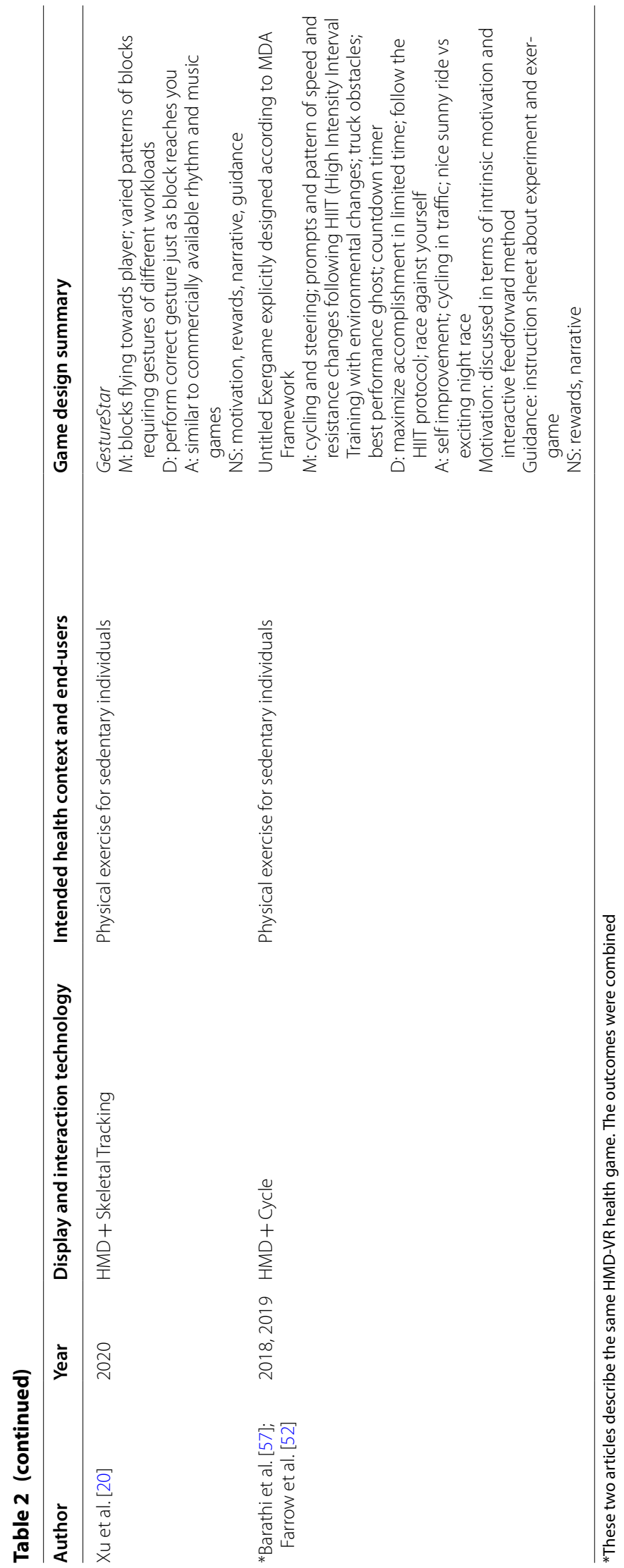


Table 3 Outcomes from evaluation of identified games

\begin{tabular}{|c|c|c|c|c|c|c|c|}
\hline Author & Year & $\begin{array}{l}\text { None } \\
\text { (system } \\
\text { overview) }\end{array}$ & $\begin{array}{l}\text { Therapeutic } \\
\text { outcome }\end{array}$ & $\begin{array}{l}\text { Game } \\
\text { experience }\end{array}$ & $\begin{array}{l}\text { Acceptance (usability, } \\
\text { usefulness, etc.) }\end{array}$ & Cybersickness & $\begin{array}{l}\text { Open } \\
\text { feedback } \\
\text { Interview }\end{array}$ \\
\hline Gobron et al. [50] & 2015 & - & - & - & $\checkmark$ & - & - \\
\hline Shaw et al. [55] & 2015 & - & $\checkmark$ & $\checkmark$ & $\checkmark$ & $\checkmark$ & $\checkmark$ \\
\hline Gromala et al. [48] & 2016 & $\checkmark$ & - & - & - & - & - \\
\hline ljaz et al. [63] & 2016 & - & - & $\checkmark$ & $\checkmark$ & - & - \\
\hline Lv et al. [65] & 2016 & $\checkmark$ & - & - & - & - & - \\
\hline Thomas et al. [71] & 2016 & - & $\checkmark$ & - & - & - & - \\
\hline Tuveri et al. [49] & 2016 & - & - & $\checkmark$ & $\checkmark$ & - & - \\
\hline Howes et al. [75] & 2017 & - & - & - & $\checkmark$ & - & $\checkmark$ \\
\hline Nielsen et al. [67] & 2017 & - & - & - & $\checkmark$ & - & - \\
\hline Ambron et al. [58] & 2018 & - & $\checkmark$ & - & $\checkmark$ & - & - \\
\hline Avola et al. [56] & 2018 & $\checkmark$ & - & - & - & - & - \\
\hline Caggianese et al. [53] & 2018 & $\checkmark$ & - & - & - & - & - \\
\hline Czub and Piskorz [59] & 2018 & - & $\checkmark$ & $\checkmark$ & $\checkmark$ & - & - \\
\hline Eisapour et al. [78] & 2018 & - & $\checkmark$ & $\checkmark$ & $\checkmark$ & - & - \\
\hline Huang et al. [61] & 2018 & - & $\checkmark$ & - & - & - & - \\
\hline Lee and Kim [64] & 2018 & - & $\checkmark$ & - & - & - & - \\
\hline Mihajlovic et al. [66] & 2018 & - & $\checkmark$ & $\checkmark$ & - & - & - \\
\hline Piskorz and Czub [68] & 2018 & - & $\checkmark$ & - & - & - & - \\
\hline Proffitt et al. [69] & 2018 & - & - & - & $\checkmark$ & - & $\checkmark$ \\
\hline Sisto et al. [54] & 2018 & $\checkmark$ & - & - & - & - & - \\
\hline Dias et al. [60] & 2019 & - & $\checkmark$ & - & $\checkmark$ & - & - \\
\hline ljaz et al [62] & 2019 & - & $\checkmark$ & $\checkmark$ & $\checkmark$ & - & - \\
\hline Nehrujee et al. [76] & 2019 & - & $\checkmark$ & - & $\checkmark$ & $\checkmark$ & - \\
\hline Rossi et al. [70] & 2019 & - & - & - & - & - & $\checkmark$ \\
\hline Tong et al. [51] & 2019 & - & $\checkmark$ & $\checkmark$ & $\checkmark$ & - & $\checkmark$ \\
\hline Yao and Kim [72] & 2019 & - & $\checkmark$ & $\checkmark$ & - & - & - \\
\hline Yaramothu et al. [73] & 2019 & - & $\checkmark$ & - & - & - & - \\
\hline Xu et al. [20] & 2020 & - & $\checkmark$ & $\checkmark$ & $\checkmark$ & $\checkmark$ & - \\
\hline $\begin{array}{l}\text { *Barathi et al. [57]; Far- } \\
\text { row et al. [52] }\end{array}$ & $2018 ; 2019$ & - & $\checkmark$ & $\checkmark$ & $\checkmark$ & - & $\checkmark$ \\
\hline
\end{tabular}

*These two articles describe the same HMD-VR health game. The outcomes were combined

during a balance training game. In an upper extremity focused game, post-stroke participants had mixed preferences [69].

Motion controls allow users to interact with virtual environments using their natural body movements. In combination with HMDs, motion control allows for designing game mechanics that rely more on such natural movements, spatial awareness, and binocular vision e.g. puzzles requiring viewing and manipulating objects from multiple angles [87]. Of the HMD-VR health games reviewed, nine relied on the headset alone. An equal number used skeletal tracking technology to capture movements of the player's body and limbs to control the game. For physical exercise, five games used stationary cycles. A few games used hand motion controllers or optical hand tracking while two others involved robots for upper limb rehabilitation. These types of motion controls allow for more intuitive interactions with virtual game environments, compared to traditional gamepads or mouse and keyboard combinations [88]. However, of the games we reviewed, game design focused less on unique mechanics afforded by HMD-VR and more on its presence and immersion advantage. However, there remains a tension between designing interactions that are intuitive (e.g. using hand movements to manipulate levers on a machine) and simple and reliable (e.g. performing complex actions by pressing a controller button) [89]. Moreover, players' familiarity with traditional game 
controls may impact their expectations and perceptions of the game [90]. Ultimately, these diverse features allow for VR applications that target a variety of health contexts. Moreover, they enable therapeutic methods that would otherwise require substantial physical resources (e.g. varied, dynamic, and highly controlled training scenarios) [91] or would not be possible (e.g. virtually exaggerated or reduced body movement) [92].

Cybersickness remains a persistent challenge in HMDVR design considerations [14]. Indeed, individuals with a history of motion sickness or cybersickness were necessarily excluded in some studies reviewed $[57,74,76]$. Moreover, the consideration for cybersickness limits game design from certain ways of implementing game mechanics, especially with respect to moving through the virtual world [93]. Porcino and colleagues have proposed some design guidelines on how to reduce cybersickness, including minimizing field of view changes not in the player's control and reducing the acceleration of movement [94]. In our review, Barathi and colleagues designed their cycling game to keep the player's view fixed forward to minimize cybersickness. Participants who played Lumapath said static and clear geometric shapes with high contrast helped them feel grounded, however the HMD's weight became uncomfortable. Yet, videogame players have also demonstrated a willingness to tolerate such usability disadvantages in exchange for a more immersive experience [89]. However, it remains unclear whether such attitudes persist in populations less familiar with videogames, or in clinical populations, where it may be exacerbated by other issues that make them more susceptible.

\section{Game design in HMD-VR health games}

HMD-VR health games presented game design with a range of detail (Table 2); 8 of 29 games lacked sufficient detail to summarize in terms of mechanics, dynamics, and aesthetics. Meaningful play, which has been previously discussed in games for health [31, 32], was not mentioned at all, while only a handful of studies framed game design in terms of designing gameplay or mechanics $[48,51,54,55,57,60,63]$. In many studies, especially those where multiple small-scale games were involved, game design was typically described as a brief scenario in terms of game controls, thematic setting, primary activity, and game outcome, which was usually a score. For example, the lower limb rehabilitation game BeTheBall for post-stroke patients was described as a scenario where players "perform at a faster path motivated by his own high-score presented in the form of a ghost [by] maximizing accuracy and velocity" and included "different types of races and environments". Such descriptions provide a rudimentary overview of the mechanics and aesthetics of the game, i.e. the rules of the game and how the designers want the player to feel while playing it. However, greater detail in the reporting of game design is required to understand how the game dynamics support moment-to-moment engagement of the player with the game. Being able to discern the actual strategies and approaches to game playing that are designed for players to enact will help us to better understand how particular game design choices work to support behavior change. In studies that did provide greater detail, few explicitly addressed game design on a theoretical level [48, 60]. Notably, one game was designed in consideration of the MDA framework [57].

As the majority of HMD-VR health games targeted physical exercise and motor rehabilitation, game design trends tended to follow the mechanics and aesthetics typical of exergames [95]. A common approach to designing the rules and structure of the VR game involved directly recreating the therapeutic task and applying points and scoring mechanics to the performance of this task. For example, cycling games for physical exercise typically tied to the power generated or distance travelled by the player to their score as they navigate obstacles $[49,55]$. Indeed, points, scoring, or prize mechanics were specified in 17 games, with many emphasizing these mechanics as key sources of motivation. Rewards-based mechanics generally give rise to game dynamics involving time pressure and striving for the highest score, with an overall game aesthetic of improvement and accumulation by overcoming challenge. For example, both Cycling Obstacle Course [55] and Rift-a-bike [49] attribute player motivation to such reward mechanics. Some games recreate scenarios involving activities of daily living with controlled parameters, allowing for graded difficulty [53, 61]. Overall, these approaches to supporting motivation lean more towards "gamification" [96, 97] of therapeutic tasks, whereby game mechanics are implemented to serve primarily as feedback and reward, similar to that provided by a coach or therapist, and less to build interesting game dynamics and aesthetics. They have the advantage of being familiar, providing direct feedback for the task, and being clear in therapeutic relevance. However, as a games that rely heavily on extrinsic rewards (points and badges), they may be limited in sustainable engagement without attention given to crafting intrinsically rewarding game experiences [98]. Barathi and colleagues [57] discussed intrinsic motivation in their exercise game, though it was still in context of scoring and overcoming challenge. In games by Ijaz and colleagues, self-determination theory was cited as underpinning motivation for playing games [63]. However, they did not discuss how it was incorporated into game design. 
Only three games involved narrative as a means of engaging end-users. For example, the upper-limb stroke rehabilitation game, "A Priest in the Air", sets the player traveling through different countries in an air balloon to reach a king, using arm movements to guide the balloon into point-scoring objects [60]. Other games simply involved aesthetics in terms of thematic setting and goals $[62,70,76]$. One game used pedaling mechanics to navigate a city and capture unique creatures [62] while another used the mechanics of capturing a flying butterfly to elicit head movements for neck rehabilitation [66]. However, these games still relied primarily on "do more to score more" dynamics.

Conversely, a few game designs involved mechanics and dynamics that focused on aesthetics of sense-pleasure, discovery, and narrative. Gobron and colleagues used the mechanics of a robotic-pedal interface as piloting controls for a spacecraft [50]; in this way the mechanics directly supported embodiment of the game aesthetic. In Mobius Floe, high levels of interactivity and multisensory elements aimed to immerse the end-user in a wintry environment. Hostile objects and combat mechanics served metaphorical roles to involve the end-user in a symbolic narrative of overcoming pain [48]. In a user study of "LumaPath", a movement-based exploratory game set in a fantastical world for individuals with arthritis, end-users emphasized that exploration was what kept them engaged as well as comfortable with learning the game [51]. The immersive advantages of HMD-VR directly support the design goal of creating these types of aesthetic experiences that focus on being present in a particular environment. In comparison, aesthetics focused on the achievement of high scores are less reliant on HMD-VR to be successful, as the experience of getting points and a high score can be equally effective when presented on a 2-dimensional display. As such, exergames focused on point-scoring may benefit from game design that employs mechanics and dynamics that better leverages the advantages of HMD-VR. The cycling game by Barathi and colleagues follows this route by creating dynamic moods of calm and urgency as the player fulfills the role of a bicycle delivery person weaving in and out of traffic [57]. At a smaller scale, multisensory design elements such as visual effects and audio cues were often pointed to specifically for providing feedback and lending sense-pleasure aesthetics: for example, particles emitting from a butterfly [66] or sounds accompanying reward collection and other events [60,70].

Overall, the HMD-VR game design discourse for health application echoes that of game design related to non-immersive VR health applications, where the focus remains on using numerical feedback and reward systems to drive motivation and engagement [80]. For example,
Burke and colleagues link meaningful play in games for stroke rehabilitation to performance feedback of the therapeutic task in the form of scoring or progress bars. Indeed, the majority of HMD-VR health games reviewed highlighted scoring points as a core mechanic.

Within the HMD-VR health games literature, there lacks a more thorough discussion of designing the game as a compelling game in-of-itself. From the games industry, one common way of discussing a game is in terms of its core loop: the primary repetitive series of actions that a player takes while interacting with the game [99]. This is the "heart" of the game and is made up of the most essential mechanics and dynamics of a game. For example, the core loop of soccer involves a cycle of positioning, dribbling, and shooting. Having a core loop that is in-of-itself compelling for players to engage with, is key to making games effective at supporting motivation and engagement with therapeutic tasks. It is what underpins the behavior change aspect of the intervention. Without creating a good core loop, one is left with an interactive virtual environment, but a potentially boring game.

Beyond a well-designed core loop, the duration of the whole health game experience should also be explicitly addressed, whether as a course of treatment spanning several sessions or something lasting years. Commercially, some games are designed to be played through once or twice, e.g. puzzle or story-driven games, while most games are designed to be played repeatedly without limit. Given the latter is an implicit objective of most health games as behavior change tools, replayability is a crucial consideration. While the concept of replayability has been touched on [32], it has not been featured as a fundamental design goal for successful health games. Nevertheless, the HMD-VR health games reviewed have used mechanics such as varied challenges, goals, and environments to support replayability [57, 74]. Cycling Obstacle Course [55] and A Priest in the Air [60] also involve decision-making through branching paths that can also support replayability. Other approaches in games industry include varied player abilities, player roles, or mechanics using randomization [100]. Oppositional games such as chess or soccer succeed in replayability by having game with large possibility spaces where players must choose amongst many approaches to playing the game and respond to their opponents' choices. Ultimately, replayability relies on game dynamics that remain interesting for players to engage with over repeated play sessions. Some academic literature has aimed to provide guidance on designing for replayability [101].

Renowned game designer Sid Meier once defined games as a series of interesting decisions [102]. Certainly, the success of a game's core loop or its replayability may be judged by how well it continuously provides 
players with such "interesting decisions." Future development of HMD-VR health games may benefit from greater attention to these design considerations. Finally, a more detailed account of game design in future reporting may facilitate more holistic evaluation and adoption of these games in clinical practice.

\section{Evaluation and adoption of HMD-VR health games}

Of the studies reviewed, 24 involved evaluation of HMDVR health games while five studies were purely descriptive of the technology (Table 3). Moreover, six studies captured qualitative user feedback using open-ended questionnaire items or semi-structured interviews. For quantitative measures, therapeutic outcomes such as energy output for exergames or visual analog scale for pain reduction were evaluated for 17 games. While these outcomes primarily serve to measure clinical status and therapeutic efficacy, they also underpin how a given therapeutic approach is translated into the game format. In terms of game design, therapeutic outcomes are often incorporated into game mechanics such as scoring or adaptive game difficulty. For example, exercise games by Barathi and colleagues as well as Shaw and colleagues reported power output of and calories burned by the player $[55,57]$. The benefit in this case is that players receive feedback that is obviously relevant to their progress in addressing their health goals. However, this approach should be used with caution, as therapeutic progress is sometimes discouragingly slow [103]. Moreover, the incorporation of therapeutic outcomes into game design should be consistent with and support game dynamics and meaningful play.

While therapeutic outcomes remain the principle indicator of a health technology's overall usefulness, adoption by users is also crucial in determining the long-term viability of a technology [104]. Adoption captures the users' inclination towards accepting and using an HMD-VR health game. Taking into account constructs contributing to adoption by users during the design and development process can support maximizing the adoption potential of health games. For example, qualitative feedback from older adults who played Lumapath highlighted a need for more guidance through the game experience to aid usability [51]. Indeed, while some of the reviewed studies relied on researchers and clinicians to provide guidance, others included instructions, videos, and in-game tutorials or practice scenes to support usability $[48,59,60,63$, $71,74]$.

Quantitatively, constructs of technology adoption were evaluated in 16 studies primarily using ad-hoc questionnaires. These included constructs such as satisfaction, motivation or willingness to use, or ease of use. Validated measures such as the System Usability Questionnaire
[105] appeared in three studies and the Intrinsic Motivation Inventory [106] was used for only one game. Similarly, 4 studies measured cybersickness either with ad-hoc Likert items or using the simulator sickness questionnaire [107]. While ad-hoc questionnaires can be tailored for the unique design goals of a HMD-VR health game, using validated measures can aid in making comparisons between games. Moreover, technology adoption theory appears largely absent from the literature reviewed. For example, the Unified Theory of Acceptance and Use of Technology (UTAUT) is a popular model for comprehensively describing the antecedents of intention-to-use technology generally $[108,109]$. Specifically, Huygelier and colleagues used the UTAUT to explore acceptance of HMD-VR by older adults [110]. Designing HMD-VR health games with consideration for adoption and usability theory may also serve to ensure any weaknesses of these games are attributable to their game design as opposed to limitations in usability.

Ultimately, the purpose of leveraging a game format is to support sustainable engagement with a therapeutic approach. As such, successful game design inherently supports adoption and serves as a means of behavior change for therapeutic adherence. In this respect, HMD-VR health games have been evaluated by how engaging an experience they are. For 12 games, gameplay experience was evaluated using ad-hoc Likert scale questionnaires, with occasional usage of more formal questionnaires such as the Game Experience Questionnaire [111] or Igroup Presence Questionnaire [112]. Overall, evaluation of gameplay experiences focused on constructs such as fun or enjoyment, immersion and presence, and game difficulty. Together, enjoyment and presence speak to how effectively the game involves the player in the aesthetic experience. Perceptions of game difficulty can indicate how well game dynamics engage or challenge players without frustrating them. However, measures of fun and enjoyment lack specificity in the multiple ways a game may succeed as an aesthetic experience. For example, participants who played LumaPath highlighted how exploration was what they liked most and aspects of the game that limited exploration detracted from their experience [51]. This is quite different from how a high intensity cycling exergame achieves an enjoyable aesthetic experience through challenge and extrinsic rewards [57]. Moreover, evaluation of gameplay experiences have typically involved impressions during or shortly after first encountering the game and with limited time to master game mechanics and dynamics. Currently, the field exists in a state of perpetual novelty. As the field of HMD-VR games for health continues to grow, understanding the qualities that distinguish more successful game design in the health context will require 
longer-term and aesthetic-oriented evaluations of gameplay experience.

\section{Stakeholder engagement}

In order to improve the adoption potential of health technologies for patients, there have been increasing calls to incorporate stakeholder engagement throughout the technology development process, with particular emphasis on involving end-users [39, 43, 113]. For HMDVR health games, key stakeholders not only include end-users, but also informal caregivers and clinicians. Stakeholder engagement in technology development encompasses a range of activities from basic user testing and feedback to more participatory or co-design oriented approaches [42].

Of the 29 HMD-VR health games reviewed, 4 indicated collaboration with clinicians for designing the game [60, $61,65,74]$. However, details of the collaboration were not typically discussed in-depth. As indicated by usability and gameplay experience outcomes, the majority of articles involved various forms of user testing, with some providing opportunity for end-users to give feedback through interview responses. These approaches generally align with user-centered design, which emphasizes iterative prototyping and testing in order to ensure products are usable and useful for end-users [114]. However, usercentered design (UCD) was not explicitly indicated as an approach in all but one of the reviewed articles [74]. In non-HMD-VR health games, UCD has been a common development approach. For example, Brox and colleagues proposed a UCD protocol specific to designing exergames for older adults. In a review of health games (including non-HMD-VR) for anxiety and depression, UCD informed the design in 7 out of 20 games [115]. Beyond UCD, which has traditionally positioned endusers as purely informants, design in research settings have seen a shift towards more collaborative and participatory approaches such as co-design [116, 117].

Engaging end-users through participatory approaches, including the field of co-design, may be particularly beneficial in the context of HMD-VR, as this context relies on more dynamic human-computer interactions with practical issues that can make implementation challenging. More participatory approaches aim to empower stakeholders as equitable partners in designing technology and are characterized by mutual commitment, learning, and alignment with stakeholder values [118]. Participatory projects may use methods such as recurrent workshops and focus groups or involve stakeholders as full team members to meaningfully incorporate stakeholder perspectives in design decisions [116]. For example, future development of games such as Lumapath may involve older adults throughout the design process to help address topics such as guidance, input simplicity, or further capitalizing on exploration as the main motivating factor, rather than identifying such considerations in later testing. As such, participatory approaches may support a more democratic method of identifying and valuing person-centered considerations regarding usability, playability, and therapeutic value early and throughout the design process of HMD-VR health games.

Of the studies reviewed, only one described engagement with end-users in the design process beyond a purely informant capacity. Eisapour and colleagues followed a participatory design approach involving both clinician users and end-users with mild cognitive impairment [74]. Their approach used focus groups and user tests to collaboratively decide on thematic setting, therapeutic exercises to include, and implementation of interactions. This process aided the authors in prototyping an exergame that aligned with end-users' preferences and addressed hidden problems early on. This example is consistent with other participatory studies in similar health technology applications. In non-gaming HMD-VR health applications, participatory methods have been used to prototype exposure therapy scenarios [119] and stress reduction treatment for teens [120]. Similarly, Webster and colleagues developed a hand rehabilitation game with people with multiple sclerosis [121]. Ultimately, participatory approaches may facilitate better game design at all levels, in fine-tuning mechanics, designing satisfying dynamics, and identifying aesthetics that resonate most strongly with a population.

\section{Limitations}

The search strategy included articles explicitly using HMD and VR as specific terms. As such, we may not have captured articles using only the general term "virtual reality." However, we deemed this strategy to have much greater specificity and identifies the most relevant articles with substantive discussion of HMD-VR.

While a narrative approach is appropriate for the range of game design descriptions present in the articles reviewed, this approach is more interpretive than systematic or scoping reviews. For example, game design summaries required more interpretation where more design details were missing. As such, the findings of this review should be received accordingly. Nevertheless, the narrative approach allows for greater flexibility in situating the particular characteristics of HMD-VR health games within the nuanced context of health technology and game design. 


\section{Conclusions}

HMD-VR health games is a relatively new and growing field of tools for engaging clients in highly immersive games designed to address health contexts ranging from rehabilitation exercise to pain management to sensory disorders. Our review provides a holistic overview of the prevailing trends in designing HMD-VR health games, including health context, game design, technology implementation and adoption, and user engagement in the development process. Overall, HMD-VR health games typically involve obstaclebased challenges, points, and extrinsic reward systems to engage clients in interventions primarily focusing on health contexts related to physical functioning and pain. The technology used to implement these games reflects this trend, with many using skeletal tracking and stationary cycles. Less common were games with emphasis on narrative experiences and use of hand motion controllers, which may better align with nonphysical exercise interventions. However, the extent to which game-based formats (versus non-game formats) or HMD-VR technology is most appropriate for less represented health contexts such as mental health requires more research. Nevertheless, we anticipate further growth in diverse and complementary HMDVR health games.

As HMD-VR technology continues to rapidly evolve, the opportunities and ways in which such games can address health contexts will continue to grow. However, these applications will continue to rely on fundamental principles of game design. Indeed, there is a reciprocal relationship between HMD-VR technology creating new design spaces for games and game design needs advancing HMD-VR technology. Given the complex intersection of this relationship with health needs, the associated game design discourse is often lacking. More in-depth and structured attention to how HMD-VR health games are designed as game experiences is needed. This will support greater understanding of what design strategies are most effective for achieving therapeutic goals, including adherence. Finally, future development HMDVR health games may benefit from more application of participatory approaches such as co-design, that involve end-users throughout the development process. Successful alignment of these games with end-users' needs and values ultimately maximizes the impact of health games by facilitating their adoption.

\section{Supplementary Information}

The online version contains supplementary material available at https://doi. org/10.1186/s12984-020-00801-3.

Additional file 1: S1. Datasheet.
Abbreviations

HMD: Head-mounted display; VR: Virtual reality; UCD: User centred design; UTAUT: Unified theory of acceptance and use of technology; MDA: Mechanicsdynamics-aesthetics framework.

\section{Acknowledgements}

Not applicable.

\section{Authors' contributions}

GT performed the literature review and prepared each section of the manuscript. BG contributed to the abstract and introduction sections and edited the complete manuscript. TT edited the complete manuscript. EC edited the complete manuscript. CS edited and finalized the manuscript. All authors read and approved the final manuscript.

Funding

This work was supported by the Lotte \& John Memorial Hecht Foundation Grant \#4110.

\section{Availability of data and materials \\ Not applicable.}

Ethics approval and consent to participate

Not applicable.

Consent for publication

Not applicable.

Competing interests

The authors declare that they have no competing interests.

\section{Author details}

${ }^{1}$ Graduate Programs in Rehabilitation Science, Faculty of Medicine, University of British Columbia, Vancouver, BC, Canada. ${ }^{2}$ School of Nursing, University of British Columbia, Vancouver, BC, Canada. ${ }^{3}$ Faculty of Science, University of British Columbia, Vancouver, BC, Canada.

Received: 10 June 2020 Accepted: 17 December 2020

Published online: 11 February 2021

References

1. Garrett B, Taverner T, Masinde W, Gromala D, Shaw C, Negraeff M. A rapid evidence assessment of immersive virtual reality as an adjunct therapy in acute pain management in clinical practice. Clin J Pain. 2014;30(12):1089-98.

2. Hoffman HG, Chambers GT, Meyer WJ, Arceneaux LL, Russell WJ, Seibel EJ, et al. Virtual reality as an adjunctive non-pharmacologic analgesic for acute burn pain during medical procedures. Ann Behav Med. 2011:41(2):183-91.

3. Li A, Montaño Z, Chen VJ, Gold Jl. Virtual reality and pain management: current trends and future directions. Pain Manag. 2011;1(2):147-57.

4. Diemer J, Mühlberger A, Pauli P, Zwanzger P. Virtual reality exposure in anxiety disorders: Impact on psychophysiological reactivity. World J Biol Psychiatry. 2014;15(6):427-42.

5. Garcia-Palacios A, Hoffman H, Carlin A, Furness TA, Botella C. Virtual reality in the treatment of spider phobia: a controlled study. Behav Res Ther. 2002;40(9):983-93.

6. Lindner P, Miloff A, Hamilton W, Reuterskiöld L, Andersson G, Powers $M B$, et al. Creating state of the art, next-generation virtual reality exposure therapies for anxiety disorders using consumer hardware platforms: design considerations and future directions. Cogn Behav Therapy. 2017;46(5):404-20.

7. Parsons TD, Rizzo AA. Affective outcomes of virtual reality exposure therapy for anxiety and specific phobias: a meta-analysis. J Behav Ther Exp Psychiatry. 2008;39(3):250-61.

8. Maples-Keller JL, Yasinski C, Manjin N, Rothbaum BO. Virtual realityenhanced extinction of phobias and post-traumatic stress. Neurotherapeutics. 2017;14(3):554-63. 
9. Ferrer-Garcia M, Gutiérrez-Maldonado J, Riva G. Virtual reality based treatments in eating disorders and obesity: a review. J Contemp Psychother. 2013;43(4):207-21.

10. Didehbani N, Allen T, Kandalaft M, Krawczyk D, Chapman S. Virtual reality social cognition training for children with high functioning autism. Comput Hum Behav. 2016;62:703-11.

11. Howard MC. A meta-analysis and systematic literature review of virtual reality rehabilitation programs. Comput Hum Behav. 2017;70:317-27.

12. Tao G, Archambault PS. Powered wheelchair simulator development: implementing combined navigation-reaching tasks with a 3D hand motion controller. J NeuroEng Rehabil. 2016;13(1):3.

13. Maggio MG, Maresca G, De Luca R, Stagnitti MC, Porcari B, Ferrera MC, et al. The growing use of virtual reality in cognitive rehabilitation: fact, fake or vision? A scoping review. J Natl Med Assoc [Internet]. 2019. http://www.sciencedirect.com/science/article/pii/S0027968418303468. Accessed 12 Feb 2019.

14. Garrett B, Taverner T, Gromala D, Tao G, Cordingley E, Sun C. Virtual reality clinical research: promises and challenges. JMIR Serious Games. 2018;6(4):e10839.

15. Sanchez-Vives MV, Slater M. From presence to consciousness through virtual reality. Nat Rev Neurosci. 2005;6(4):332-9.

16 Borrego A, Latorre J, Alcañiz M, Llorens R. Embodiment and presence in virtual reality after stroke. A comparative study with healthy subjects. Front Neurol. 2019. https://doi.org/10.3389/fneur.2019.01061/full.

17. Osimo SA, Pizarro R, Spanlang B, Slater M. Conversations between self and self as Sigmund Freud-A virtual body ownership paradigm for self counselling. Sci Rep. 2015;5(1):13899.

18. Slater M, Lotto B, Arnold MM, Sánchez-Vives MV. How we experience immersive virtual environments: the concept of presence and its measurement. 2009; http://diposit.ub.edu/dspace/handle/2445/49643. Accessed 28 Sep 2020.

19 Gorisse G, Christmann O, Amato EA, Richir S. First- and third-person perspectives in immersive virtual environments: presence and performance analysis of embodied users. Front Robot Al. 2017. https://doi. org/10.3389/frobt.2017.00033/full.

20. Salamin P, Tadi T, Blanke O, Vexo F, Thalmann D. Quantifying effects of exposure to the third and first-person perspectives in virtual-realitybased training. IEEE Trans Learn Technol. 2010;3(3):272-6.

21. Jerdan SW, Grindle M, van Woerden HC, Boulos MNK. Head-mounted virtual reality and mental health: critical review of current research. JMIR Serious Games. 2018;6(3):e14.

22. Gromala D, Tong X, Choo A, Karamnejad M, Shaw CD. The virtual meditative walk: virtual reality therapy for chronic pain management. In: Proceedings of the 33rd annual ACM conference on human factors in computing systems. New York, NY, USA: ACM; 2015. p. 521-524. (CHI '15). http://doi.acm.org/https://doi.org/10.1145/2702123.2702344. Accessed 8 Aug 2020.

23. Fitterer D. Audioshield [Video game]. Dylan Fitterer; 2016.

24. Beat Games. Beat Saber [Video game]. Beat Games; 2019.

25. Cheok G, Tan D, Low A, Hewitt J. Is Nintendo Wii an effective intervention for individuals with stroke? A systematic review and meta-analysis. J Am Med Direct Assoc. 2015;16(11):923-32.

26. Goble DJ, Cone BL, Fling BW. Using the Wii Fit as a tool for balance assessment and neurorehabilitation: the first half decade of "Wii-search." J Neuroeng Rehabil. 2014;11:12.

27. Tao G, Miller WC, Eng JJ, Lindstrom H, Imam B, Payne M. Self-directed usage of an in-home exergame after a supervised telerehabilitation training program for older adults with lower-limb amputation. Prosthet Orthot Int. 2020;44(2):52-9.

28 Bond S, Laddu DR, Ozemek C, Lavie CJ, Arena R. Exergaming and virtual reality for health: implications for cardiac rehabilitation. Curr Probl Cardiol. 2019. https://doi.org/10.1016/j.cpcardiol.2019.100472.

29. Bonnechère B, Jansen B, Omelina L, Van Sint JS. The use of commercial video games in rehabilitation: a systematic review. Int J Rehabil Res. 2016;39(4):277-90.

30. Baranowski T, Buday R, Thompson DI, Baranowski J. Playing for real: video games and stories for health-related behavior change. Am J Prev Med. 2008;34(1):74-82.e10.

31. Barrett N, Swain I, Gatzidis C, Mecheraoui C. The use and effect of video game design theory in the creation of game-based systems for upper limb stroke rehabilitation. J Rehabil Assist Technol Eng. 2016;3:2055668316643644.

32. Burke JW, McNeill MDJ, Charles DK, Morrow PJ, Crosbie JH, McDonough SM. Optimising engagement for stroke rehabilitation using serious games. Vis Comput. 2009;25(12):1085.

33. Turner WA, Thomas B, Casey LM. Developing games for mental health: a primer. Prof Psychol Res Pract. 2016;47(3):242-9.

34 Maier M, Rubio Ballester B, Duff A, Duarte Oller E, Verschure PFMJ. Effect of specific over nonspecific VR-based rehabilitation on poststroke motor recovery: a systematic meta-analysis. Neurorehabil Neural Repair. 2019. https://doi.org/10.1177/1545968318820169.

35. Salen KS, Zimmerman E. Rules of play: game design fundamentals. 1st ed. Cambridge: The MIT Press; 2003. p. 688.

36. Schell J. The art of game design : a book of lenses, Second Edition [Internet]. A K Peters/CRC Press; 2014. https://www.taylorfrancis.com/ books/9781466598676. Accessed 11 Feb 2019.

37. Fagerholt E, Lorentzon M. Beyond the HUD-user interfaces for increased player immersion in FPS games [Internet]. Chalmers University of Technology; 2009. https://odr.chalmers.se/handle/20.500.12380 /111921. Accessed 14 Apr 2020.

38. Hunicke R, LeBlanc M, Zubek R. MDA: a formal approach to game design and game research. Proc AAAI Workshop Chall Game Al. 2004;4(1):5.

39. Robillard JM, Cleland I, Hoey J, Nugent C. Ethical adoption: a new imperative in the development of technology for dementia. Alzheimer's Dement. 2018;14(9):1104-13.

40. Fox G, Connolly R. Mobile health technology adoption across generations: narrowing the digital divide. Inf Syst J. 2018;28(6):995-1019.

41. Yusif S, Soar J, Hafeez-Baig A. Older people, assistive technologies, and the barriers to adoption: a systematic review. Int J Med Informat. 2016:1(94):112-6.

42. Boaz A, Hanney S, Borst R, O'Shea A, Kok M. How to engage stakeholders in research: design principles to support improvement. Health Res Policy Syst. 2018;16(1):60.

43. Harte R, Glynn L, Rodríguez-Molinero A, Baker PM, Scharf T, Quinlan LR, et al. A human-centered design methodology to enhance the usability, human factors, and user experience of connected health systems: a three-phase methodology. JMIR Hum Factors. 2017;4(1):e8.

44. Borrego A, Latorre J, Alcañiz M, Llorens R. Comparison of oculus rift and HTC vive: feasibility for virtual reality-based exploration, navigation, exergaming, and rehabilitation. Games Health J. 2018;7(3):151-6.

45 Chirico A, Lucidi F, Laurentiis MD, Milanese C, Napoli A, Giordano A. Virtual reality in health system: beyond entertainment. A minireview on the efficacy of VR during cancer treatment. J Cell Physiol. 2016;231(2):275-87

46 Jerald J. The VR book: human-centered design for virtual reality. California: Morgan \& Claypool; 2015. p. 637

47. Pallavicini F, Pepe A, Minissi ME. Gaming in virtual reality: what changes in terms of usability, emotional response and sense of presence compared to non-immersive video games? Simul Gaming. 2019:50(2):136-59.

48. Gromala D, Tong X, Shaw C, Amin A, Ulas S, Ramsay G. Mobius Floe: an immersive virtual reality game for pain distraction. Electronic Imaging. 2016;2016(4):1-5.

49. Tuveri E, Macis L, Sorrentino F, Spano L, Scateni R. Fitmersive games: fitness gamification through immersive VR. 2016. p. 212-5.

50. Gobron SC, Zannini N, Wenk N, Schmitt C, Charrotton Y, Fauquex A, et al. Serious games for rehabilitation using head-mounted display and haptic devices. In: De Paolis LT, Mongelli A, editors., et al., Augmented and virtual reality. Cham: Springer International Publishing; 2015. p. 199-219.

51. Tong X, Gromala D, Machuca F. LumaPath: an immersive virtual reality game for encouraging physical activity for senior arthritis patients. In: Chen JYC, Fragomeni G, editors. Virtual, augmented and mixed reality applications and case studies. Cham: Springer International Publishing; 2019. p. 384-97.

52. Farrow M, Lutteroth C, Rouse PC, Bilzon JLJ. Virtual-reality exergaming improves performance during high-intensity interval training. Eur J Sport Sci. 2019;19(6):719-27.

53. Caggianese G, Chirico A, De Pietro G, Gallo L, Giordano A, Predazzi $M$, et al. Towards a virtual reality cognitive training system for mild 
cognitive impairment and Alzheimer's disease patients. In: 2018 32nd International Conference on Advanced Information Networking and Applications Workshops (WAINA). 2018. p. 663-7.

54. Sisto M, Zare M, Ouerhani N, Bolinhas C, Divernois M, Mignot B, et al. Virtual reality serious game for musculoskeletal disorder prevention. In: De Paolis LT, Bourdot P, editors., et al., Augmented reality, virtual reality, and computer graphics. Cham: Springer International Publishing; 2018. p. 43-59.

55. Shaw LA, Wünsche BC, Lutteroth C, Marks S, Buckley J, Corballis P. Development and evaluation of an exercycle game using immersive technologies. In: Proceedings of the 8th Australasian Workshop on Health Informatics and Knowledge Management (HIKM), 2015: Volume 164 [Internet]. Australian Computer Society; 2015. p. 75-85. https:// researchportal.bath.ac.uk/en/publications/development-and-evalu ation-of-an-exercycle-game-using-immersive-t. Accessed 29 Feb 2020.

56. Avola D, Cinque L, Foresti GL, Marini MR, Pannone D. VRheab: a fully immersive motor rehabilitation system based on recurrent neural network. Multimed Tools Appl. 2018;77(19):24955-82.

57. Barathi SC, Finnegan DJ, Farrow M, Whaley A, Heath P, Buckley J, et al. Interactive feedforward for improving performance and maintaining intrinsic motivation in VR exergaming. In: Proceedings of the 2018 $\mathrm{CHI}$ conference on human factors in computing systems [Internet]. Montreal QC, Canada: Association for Computing Machinery; 2018. p. 1-14. (CHI '18). https://doi.org/https://doi.org/10.1145/3173574.31739 82. Accessed 29 Feb 2020.

58 Ambron E, Miller A, Kuchenbecker KJ, Buxbaum LJ, Coslett HB. Immersive low-cost virtual reality treatment for phantom limb pain: evidence from two cases. Front Neurol. 2018. https://doi.org/10.3389/fneur 2018.00067/full.

59. Czub M, Piskorz J. Body movement reduces pain intensity in virtual reality-based analgesia. Int J Hum-Comput Interact. 2018:34(11):1045-51.

60. Dias J, Veloso Al, Ribeiro T. A priest in the air. In: 2019 14th Iberian Conference on Information Systems and Technologies (CISTI). 2019. p. 1-7.

61. Huang X, Naghdy F, Du H, Naghdy G, Murray G. Design of adaptive control and virtual reality-based fine hand motion rehabilitation system and its effects in subacute stroke patients. Comput Methods Biomech Biomed Eng Imaging Visual. 2018;6(6):678-86.

62. Ijaz K, Wang Y, Ahmadpour N, Calvo RA. Immersive VR exergames for health and wellbeing. In: Extended abstracts of the 2019 CHI conference on human factors in computing systems [Internet]. Glasgow, Scotland Uk: Association for Computing Machinery; 2019. p. 1-4. (CHI EA '19). https://doi.org/https://doi.org/10.1145/3290607.3313281

63. Ijaz K, Wang Y, Milne D, Calvo RA. Competitive vs affiliative design of immersive VR exergames. In: Marsh T, Ma M, Oliveira MF, Baalsrud Hauge J, Göbel S, editors. Serious games. Cham: Springer International Publishing; 2016. p. 140-50.

64. Lee H-J, Kim S-J. Effectiveness of binocularity-stimulating treatment in children with residual amblyopia following occlusion. BMC Ophthalmol. 2018;18(1):253.

65. Lv Z, Chirivella J, Gagliardo P. Bigdata oriented multimedia mobile health applications. J Med Syst. 2016;40(5):120.

66. Mihajlovic Z, Popovic S, Brkic K, Cosic K. A system for head-neck rehabilitation exercises based on serious gaming and virtual reality. Multimed Tools Appl. 2018;77(15):19113-37.

67. Nielsen R, Henriksen B, Kraus M, Geng B. Comparison of body positions in virtual reality mirror box therapy for treatment of phantom limb pain in lower limb amputees. In: Proceedings of the virtual reality international conference - laval virtual 2017 [Internet]. Laval, France: Association for Computing Machinery; 2017. p. 1-2. (VRIC '17). https:// doi.org/https://doi.org/10.1145/3110292.3110307

68. Piskorz J, Czub M. Effectiveness of a virtual reality intervention to minimize pediatric stress and pain intensity during venipuncture. J Special Pediatric Nurs. 2018;23(1):e12201.

69. PROFFITT R, WARREN J, LANGE B, CHANG C-Y. Safety and Feasibility of a First-Person View, Full-Body Interaction Game for Telerehabilitation Post-Stroke. Int J Telerehabil. 2018 Aug 3;10(1):29-36.

70. Rossi H, Prates R, Santos S, Ferreira R. Development of a virtual realitybased game approach for supporting sensory processing disorders treatment. Information. 2019;10(5):177.
71. Thomas JS, France CR, Applegate ME, Leitkam ST, Pidcoe PE, Walkowski S. Effects of visual display on joint excursions used to play virtual dodgeball. JMIR Serious Games. 2016;4(2):e16.

72 Yao S, Kim G. The effects of immersion in a virtual reality game: presence and physical activity. In: Fang X, editor. $\mathrm{HCl}$ in games. Cham: Springer International Publishing; 2019. p. 234-42.

73 Yaramothu C, Vito d'Antonio-Bertagnolli J, Santos EM, Crincoli PC, Rajah $\mathrm{JV}$, Scheiman M, et al. Proceedings \#37: virtual eye rotation vision exercises (VERVE): a virtual reality vision therapy platform with eye tracking. Brain Stimul. 2019;12(2):107-8.

74. Eisapour M, Cao S, Domenicucci L, Boger J. Participatory design of a virtual reality exercise for people with mild cognitive impairment. In: Extended Abstracts of the $2018 \mathrm{CHI}$ Conference on Human Factors in Computing Systems - CHI '18 [Internet]. Montreal QC, Canada: ACM Press; 2018. p. 1-9. http://dl.acm.org/citation.cfm?doid=3170427.31743 62. Accessed 14 Dec 2019.

75. Howes S, Charles D, Holmes D, Pedlow K, Wilson I, McDonough S. Older adults' experience of falls prevention exercise delivered using active gaming and virtual reality. Physiotherapy. 2017;1 (103):e4-5.

76. Nehrujee A, Vasanthan L, Lepcha A, Balasubramanian S. A Smartphonebased gaming system for vestibular rehabilitation: a usability study. J Vestib Res. 2019;29(2-3):147-60.

77. Xu W, Liang H-N, Zhang Z, Baghaei N. Studying the effect of display type and viewing perspective on user experience in virtual reality exergames. Games Health J. 2020. https://doi.org/10.1089/g4h.2019.0102.

78. Dascal J, Reid M, IsHak WW, Spiegel B, Recacho J, Rosen B, et al. Virtual reality and medical inpatients: a systematic review of randomized. Controll Trials Innov Clin Neurosci. 2017;14(1-2):14-21.

79. Lin H-T, Li Y-I, Hu W-P, Huang C-C, Du Y-C. A scoping review of the efficacy of virtual reality and exergaming on patients of musculoskeletal system disorder. J Clin Med. 2019;8(6):791.

80 "Skip" Rizzo A, Koenig ST. Is clinical virtual reality ready for primetime? Neuropsychology. 2017;31(8):877-99.

81. Li J, Theng Y-L, Foo S. Effect of exergames on depression: a systematic review and meta-analysis. Cyberpsychol Behav Soc Netw. 2016;19(1):34-42.

82. McMahan RP, Bowman DA, Zielinski DJ, Brady RB. Evaluating display fidelity and interaction fidelity in a virtual reality game. IEEE Trans Visual Comput Graphics. 2012;18(4):626-33.

83. Tao G, Archambault PS, Levin MF. Evaluation of kinect skeletal tracking in a virtual reality rehabilitation system for upper limb hemiparesis. In: 2013 International Conference on Virtual Rehabilitation (ICVR). 2013. p. 164-5.

84. Khademi M, Mousavi Hondori H, McKenzie A, Dodakian L, Lopes CV, Cramer SC. Free-hand interaction with leap motion controller for stroke rehabilitation. In: $\mathrm{CHI}$ '14 Extended Abstracts on Human Factors in Computing Systems [Internet]. Toronto, Ontario, Canada: Association for Computing Machinery; 2014. p. 1663-1668. (CHI EA '14). https://doi. org/https://doi.org/10.1145/2559206.2581203.

85. Shelstad WJ, Smith DC, Chaparro BS. Gaming on the rift: how virtual reality affects game user satisfaction. Proc Hum Factors Ergon Soc Ann Meet. 2017;61(1):2072-6.

86 Pallavicini F, Ferrari A, Zini A Garcea G, Zanacchi A, Barone G, et al. What distinguishes a traditional gaming experience from one in virtual reality? An exploratory study. In: Ahram T, Falcão C, editors., et al., Advances in human factors in wearable technologies and game design. Cham: Springer International Publishing; 2017. p. 225-31.

87. Garrett BM, Tao G, Taverner T, Cordingley E, Sun C. Patients perceptions of virtual reality therapy in the management of chronic cancer pain. Heliyon. 2020;6(5):e03916.

88. Seibert J, Shafer DM. Control mapping in virtual reality: effects on spatial presence and controller naturalness. Virtual Real. 2018;22(1):79-88

89. Porter III J, Boyer M, Robb A. Guidelines on successfully porting nonimmersive games to virtual reality: a case study in minecraft. In: The annual symposium on computer-human interaction in play extended abstracts-CHI PLAY '18 [Internet]. Melbourne, VIC, Australia: ACM Press; 2018. p. 405-15. http://dl.acm.org/citation.cfm?doid=3242671.32426 77. Accessed 31 Dec 2019

90. Martel E, Muldner K. Controlling VR games: control schemes and the player experience. Entertain Comput. 2017;1 (21):19-31. 
91. Nunnerley J, Gupta S, Snell D, King M. Training wheelchair navigation in immersive virtual environments for patients with spinal cord injuryend-user input to design an effective system. Disabil Rehabil Assist Technol. 2017;12(4):417-23.

92. Chen KB, Sesto ME, Ponto K, Leonard J, Mason A, Vanderheiden G, et al. Use of virtual reality feedback for patients with chronic neck pain and kinesiophobia. IEEE Trans Neural Syst Rehabil Eng. 2017;25(8):1240-8.

93. Clifton J, Palmisano S. Effects of steering locomotion and teleporting on cybersickness and presence in HMD-based virtual reality. Virtual Reality. 2020;24(3):453-68.

94. Porcino TM, Clua E, Trevisan D, Vasconcelos CN, Valente L. Minimizing cyber sickness in head mounted display systems: design guidelines and applications. In: 2017 IEEE 5th International Conference on Serious Games and Applications for Health (SeGAH). 2017. p. 1-6.

95. Skjæret N, Nawaz A, Morat T, Schoene D, Helbostad JL, Vereijken B. Exercise and rehabilitation delivered through exergames in older adults: an integrative review of technologies, safety and efficacy. Int J Med Inf. 2016;85(1):1-16.

96. Deterding S, Dixon D, Khaled R, Nacke L. From game design elements to gamefulness: defining "gamification." In: Proceedings of the 15th International Academic MindTrek Conference on Envisioning Future Media Environments - MindTrek'11 [Internet]. Tampere, Finland: ACM Press; 2011. p. 9. http://dl.acm.org/citation.cfm?doid=2181037.21810 40. Accessed 7 Mar 2020.

97. Johnson D, Deterding S, Kuhn K-A, Staneva A, Stoyanov S, Hides L. Gamification for health and wellbeing: a systematic review of the literature. Internet Intervent. 2016;1 (6):89-106.

98 Richter G, Raban DR, Rafaeli S. Studying gamification: the effect of rewards and incentives on motivation. In: Reiners T, Wood LC, editors. Gamification in education and business. Cham: Springer International Publishing; 2015. p. 21-46. https://doi.org/10.1007/978-3-319-10208 -5_2.

99. Lovato N. How to perfect your game's core loop. GameAnalytics. 2017. https://gameanalytics.com/blog/how-to-perfect-your-games-coreloop.html. Accessed 27 Apr 2020.

100. Brycer J. A study into replayability—defining variance [Internet]. Gamasutra. 2018. https://www.gamasutra.com/blogs/JoshBycer/20180 521/318337/A_Study_Into_Replayability__Defining_Variance.php. Accessed 27 Apr 2020.

101. Krall J, Menzies T. Aspects of Replayability and Software Engineering: Towards a Methodology of Developing Games. 2012. http://www.scirp .org/journal/Paperlnformation.aspx?PaperlD=19725. Accessed 8 Mar 2020

102. Alexander L. GDC 2012: Sid Meier on how to see games as sets of interesting decisions [Internet]. Gamasutra. 2012./view/news/164869/ GDC_2012_Sid_Meier_on_how_to_see_games_as_sets_of_interesting_decisions.php. Accessed 6 Mar 2020.

103. Dixon G, Thornton EW, Young CA. Perceptions of self-efficacy and rehabilitation among neurologically disabled adults. Clin Rehabil. 2007;21(3):230-40.

104. Heart T, Kalderon E. Older adults: are they ready to adopt health-related ICT? Int J Med Inf. 2013;82(11):e209-31.

105. Bangor A, Kortum PT, Miller JT. An empirical evaluation of the system usability scale. Int J Hum Comput Interact. 2008;24(6):574-94.

106. McAuley E, Duncan T, Tammen VV. Psychometric properties of the intrinsic motivation inventory in a competitive sport setting: a confirmatory factor analysis. Res Q Exerc Sport. 1989;60(1):48-58.
107. Kennedy RS, Lane NE, Berbaum KS, Lilienthal MG. Simulator sickness questionnaire: an enhanced method for quantifying simulator sickness. Int J Aviat Psychol. 1993;3(3):203-20.

108. Venkatesh V, Morris MG, Davis GB, Davis FD. User acceptance of information technology: toward a unified view. MIS Q. 2003;27(3):425-78.

109. Venkatesh V, Thong JYL, Xu X. Consumer acceptance and use of information technology: extending the unified theory of acceptance and use of technology. MIS Q. 2012;36(1):157-78.

110. Huygelier H, Schraepen B, van Ee R, Abeele VV, Gillebert CR. Acceptance of immersive head-mounted virtual reality in older adults. Sci Rep. 2019;9(1):1-12.

111. IJsselsteijn WA, Kort YAW de, Poels K. The game experience questionnaire. 2013. https://research.tue.nl/en/publications/the-game-exper ience-questionnaire. Accessed 11 Apr 2020.

112. Schubert TW. The sense of presence in virtual environments: a threecomponent scale measuring spatial presence, involvement, and realness. Zeitschrift für Medienpsychologie. 2003;15(2):69-71.

113. Domecq JP, Prutsky G, Elraiyah T, Wang Z, Nabhan M, Shippee N, et al. Patient engagement in research: a systematic review. BMC Health Serv Res. 2014;14(1):89.

114. Abras C, Maloney-Krichmar D, Preece J. User-centered design. In: Bainbridge W, editor. Encyclopedia of human-computer interaction. Thousand Oaks: Sage Publications; 2004.

115. Dekker MR, Williams AD. The use of user-centered participatory design in serious games for anxiety and depression. Games Health J. 2017:6(6):327-33.

116. Halskov K, Hansen NB. The diversity of participatory design research practice at PDC 2002-2012. Int J Hum Comput Stud. 2015;1 (74):81-92.

117 Sanders EB-N, Stappers PJ. Co-creation and the new landscapes of design. CoDesign. 2008;4(1):5-18.

118. Frauenberger C, Good J, Fitzpatrick G, Iversen OS. In pursuit of rigour and accountability in participatory design. Int J Hum Comput Stud. 2015;1(74):93-106.

119. Flobak E, Wake JD, Vindenes J, Kahlon S, Nordgreen T, Guribye F. Participatory design of VR scenarios for exposure therapy. In: Proceedings of the 2019 CHI Conference on Human Factors in Computing SystemsCHI'19 [Internet]. Glasgow: ACM Press; 2019. p. 1-12. http://dl.acm.org/ citation.cfm?doid=3290605.3300799. Accessed 5 Jan 2020.

120. Björling EA, Cicero R, Sankar A, Sekar A. Thought disposal: co-designing a virtual interaction to reduce stress in teens. In: Proceedings of the Interaction Design and Children on ZZZ - IDC '19 [Internet]. Boise, ID, USA: ACM Press; 2019. p. 562-7. http://dl.acm.org/citation. cfm?doid =3311927.3325313. Accessed 5 Jan 2020.

121. Webster A, Poyade M, Rea P, Paul L. The co-design of hand rehabilitation exercises for multiple sclerosis using hand tracking system. In: Rea PM, editor. Biomedical visualisation. Cham: Springer International Publishing; 2019. p. 83-96.

\section{Publisher's Note}

Springer Nature remains neutral with regard to jurisdictional claims in published maps and institutional affiliations.

Ready to submit your research? Choose BMC and benefit from:

- fast, convenient online submission

- thorough peer review by experienced researchers in your field

- rapid publication on acceptance

- support for research data, including large and complex data types

- gold Open Access which fosters wider collaboration and increased citations

- maximum visibility for your research: over $100 \mathrm{M}$ website views per year

At BMC, research is always in progress.

Learn more biomedcentral.com/submissions 